\title{
Inappropriateness of health care in Canada: a systematic review protocol
}

Janet E. Squires ${ }^{1,2^{*}}$ (D), lan D. Graham ${ }^{1,3}$, Doris Grinspun ${ }^{4}$, John Lavis ${ }^{5}$, France Légaré6,7,8, Robert Bell ${ }^{9}$, Stephen Bornstein ${ }^{10,11}$, Susan E. Brien ${ }^{12}$, Mark Dobrow ${ }^{13}$, Megan Greenough ${ }^{2}$, Carole A. Estabrooks ${ }^{14}$, Michael Hillmer ${ }^{15}$, Tanya Horsley ${ }^{16}$, Alan Katz ${ }^{17}$, Christina Krause ${ }^{18}$, Wendy Levinson ${ }^{19}$, Adrian Levy ${ }^{20}$, Michelina Mancuso ${ }^{21}$, Alies Maybee ${ }^{22}$, Steve Morgan ${ }^{23}$, Letitia Nadalin Penno 2,24, Andrew Neuner ${ }^{25}$, Tamara Rader $^{26}$, Janet Roberts ${ }^{27}$, Gary Teare ${ }^{28}$, Joshua Tepper ${ }^{29}$, Amanda Vandyk ${ }^{30}$, Denise Widmeyer ${ }^{31}$, Michael Wilson ${ }^{5}$ and Jeremy M. Grimshaw ${ }^{32}$

\begin{abstract}
Background: There is increasing recognition in Canada and globally that a substantial proportion of health care delivered is inappropriate as evidenced by (1) harmful and/or ineffective practices being overused, (2) effective clinical practices being underused, and (3) other clinical practices being misused. Inappropriate health care leads to negative patient experiences, poor health outcomes, and inefficient use of scarce health care resources. The purpose of this study is to conduct a systematic review of inappropriate health care in Canada. Our specific objectives are to (1) systematically search and critically review published and grey literature for studies on inappropriate health care in Canada; (2) estimate the nature and magnitude of inappropriate health care in Canada and its provincial and territorial jurisdictions.
\end{abstract}

Methods: We will include all quantitative study designs reporting objective or subjective measurements of inappropriate health care in Canada over the last 10 years. We will search the following online databases: MEDLINE, Cochrane Central Register of Controlled Trials, EconLit, and ISI-Web of Knowledge, which contains Web of Science Core Collection-Citation Indexes, Science Citation Index Expanded, Conference Proceedings Citation Index-Science, and Conference Proceedings Citation Index-Social Science \& Humanities. We will also search grey literature sources to identify provincial and national audits of inappropriate health care. Two authors will independently screen, assess data quality, and extract data for synthesis. Study findings will be synthesized narratively. We will organize our data into three care categorizations: preventive care, acute care, and chronic care. We will provide a compendium of inappropriate health care for each care category for Canada and each Canadian province and territory, where sufficient data exists, by calculating (1) overall medians of underuse, overuse, and misuse of clinical practices and (2) the range of medians of underuse, overuse, and misuse for each clinical practice investigated.

Discussion: This review will result in the first-ever evidence-based compendium of inappropriate health care in Canada. We will also develop detailed reports of inappropriate health care for each Canadian province and territory.

\section{Systematic review registration: PROSPERO CRD42018093495}

Keywords: Quality of health care, Health services research, Delivery of health care

\footnotetext{
* Correspondence: janet.squires@uottawa.ca

${ }^{1}$ Clinical Epidemiology Program, Ottawa Hospital Research Institute, 501

Smyth Road, P.O. Box 201-B, Ottawa, Ontario K1H 8L6, Canada

${ }^{2}$ Faculty of Health Sciences, School of Nursing, University of Ottawa, Ottawa,

Canada

Full list of author information is available at the end of the article
}

(C) The Author(s). 2019 Open Access This article is distributed under the terms of the Creative Commons Attribution 4.0 International License (http://creativecommons.org/licenses/by/4.0/), which permits unrestricted use, distribution, and reproduction in any medium, provided you give appropriate credit to the original author(s) and the source, provide a link to the Creative Commons license, and indicate if changes were made. The Creative Commons Public Domain Dedication waiver (http://creativecommons.org/publicdomain/zero/1.0/) applies to the data made available in this article, unless otherwise stated. 


\section{Background}

As health systems in Canada and around the world struggle with sustainability [1], there is increasing recognition that a substantial proportion of the health care delivered is clearly inappropriate as evidenced by (1) harmful and/or ineffective clinical practices being overused, (2) effective clinical practices being underused, and (3) other clinical practices being misused [2-10]. Several studies have highlighted the negative effects that inappropriate health care may have on patients. In a study by Baker and colleagues [11], 20 hospitals were randomly chosen across 5 provinces in Canada (British Columbia, Alberta, Ontario, Quebec, and Nova Scotia) to identify adverse events and their preventability: an adverse event being defined as an unintended injury or complication, resulting in disability, death, or a prolonged hospital stay [11]. The methods of this study were based on several global studies from Australia [12], the UK [13], New Zealand [14-16], Denmark [17], and the USA [18-20]. A screening process was completed in 4164 hospital admissions, and physician reviewers identified a total of 1133 injuries or complications in 858 charts. In 401 of those charts (46.7\%), the adverse events resulted in death, disability at the time of discharge, or prolonged hospital stay [11]. Overall, $7.5 \%$ of patients experienced one or more adverse event and $36.9 \%$ of those patients experienced highly preventable adverse events [11]. In response, there is widespread professional and policy interest in reducing such inappropriate health care in Canada. For example, in 2014 Choosing Wisely Canada (CWC), a campaign designed to help clinicians and patients engage in conversations about unnecessary tests/ treatments, and make optimal choices to ensure high-quality appropriate health care, was established [21]. CWC, modeled after the US Choosing Wisely campaign, is physician-led in partnership with the Canadian Medical Association and is now endorsed by all provincial/territorial medical associations in Canada [21].

Inappropriate health care leads to negative patient experiences [22], poor health outcomes [23, 24], and inefficient use of scarce health care resources [25]. Summaries of inappropriate health care, each revealing astonishingly high levels, exist for the USA [2, 9], the UK [4], and Australia [5]; no summary exists for Canada. In the USA, performance in preventive, acute, and chronic care was evaluated; care was found to be inappropriate (i.e., overused or underused) in all three care areas, with $30 \%$ of patients receiving inappropriate acute care services, $40 \%$ receiving inappropriate chronic care services, and $50 \%$ receiving inappropriate preventive care services [2]. A second more recent review in the USA focused only on overuse, one dimension of inappropriate care; overuse rates were substantial, ranging from a high of $89 \%$ for antibiotic use in upper respiratory tract infections to a low of $1.4 \%$ for coronary artery bypass graft [9]. In the UK, performance in primary care was evaluated and care was found to be inappropriate more often than not, ranging from a high of $97 \%$ inappropriate care for diabetic foot examination to a low of $51 \%$ for diabetic fundal examinations [4]. In Australia, performance in primary care was also evaluated; patients received inappropriate care in $43 \%$ of encounters, ranging from a high of $87 \%$ inappropriate care for alcohol dependence to a low of $10 \%$ for coronary artery disease [5]. These reviews have provided much needed additions to the field of health care quality by confirming that inappropriate health care is a serious and widespread problem, and one to which no health sector is immune. These reviews also laid the foundation for several highly successful quality improvement initiatives, e.g., the 100,000 Lives and Protecting 5 Million Lives from Harm campaigns in the USA and Safer Healthcare Now! in Canada, which led to substantial reductions in inappropriate health care resulting in large numbers of saved lives [26, 27].

While no comparable comprehensive synthesis of inappropriate health care exists in Canada, it is reasonable to assume that similar high levels of inappropriate care exist in Canada. However, we do not know which types of care are inappropriately delivered; whether they are overused, underused, or misused; or how this inappropriate use may vary by province/territory, and the jurisdictional unit in Canada where most practice optimization efforts take place [2]. As a result, it is currently difficult to make informed judgments about which clinical practices to prioritize and where to focus quality improvement efforts in Canada. This task is further complicated by the fact that Canada does not presently have a mandatory comprehensive national quality tracking system. While the Canadian Institute for Health Information (CIHI), an independent organization that provides information on Canada's health system and the health of Canadians, houses multiple pan-Canadian databases spanning different health sectors, it does not collect information on all clinical practices and contributions to their databases vary greatly by jurisdiction and health sector. Thus, in the absence of a mandatory and more comprehensive national quality tracking system, a systematic summary of published and grey literature is the best way to provide an overview of inappropriate health care in Canada [7].

\section{Defining inappropriate health care}

Inappropriate health care is a core component of health care quality, which is a multidimensional concept comprised of (1) structure (organizational factors that define the health system, includes physical and staff characteristics); (2) care processes (interactions between users, includes clinical care and interpersonal care); and (3) outcomes (consequences of care) [28, 29]. In 
our review, we will focus on inappropriate health care (which are care processes), because this is the dimension of health care quality that is associated with the most waste in health care [2].

A scoping review [30] of health care appropriateness revealed two dimensions to the concept: (1) appropriate health care and (2) inappropriate health care. Both dimensions were consistently defined across studies: appropriate health care in terms of positive effects for patients and inappropriate health care in terms of negative effects for patients [30-34]. This notion of positive and negative effects was explicitly defined by researchers at the RAND Corporation (23) with the introduction of risks and benefits. According to RAND, a clinical practice was considered to be inappropriate when the "risks exceeded the expected benefit" [34] (p. 669). This definition applies to an "average patient" presenting to an "average physician" [30, 35]. Building on the RAND definition of inappropriate health care, several conceptual frameworks emerged that shed further light on what constitutes inappropriate health care. In 1996, Lavis [6] published a framework proposing that health care could be inappropriate along two dimensions: (1) the clinical practice (e.g., administration of a drug) and (2) the setting where the service is delivered (e.g., hospital). In this framework, an inappropriate clinical practice is one that is "not expected to benefit the patient or, in the more extreme case, may harm the patient" [6] (p. 326). In a second framework, Sharpe and Faden [32] furthered our understanding of inappropriate care by asserting that it includes both under- and overuse of clinical practices [32]. A third framework, from the US National Roundtable on Health Care Quality [36], used a tripartite classification to describe inappropriate health care: (1) underuse, (2) overuse, and (3) misuse. Underuse refers to a failure to provide a clinical practice when patient benefits clearly outweigh the risks (e.g., missing a childhood immunization for measles) [36]. Overuse occurs when a clinical practice is provided under circumstances in which its potential for harm exceeds the possible benefit (e.g., prescribing an antibiotic for a viral infection for which antibiotics are ineffective) [36]. Misuse occurs when an appropriate practice is selected but a preventable complication occurs resulting in the patient not receiving the full potential benefit of the practice (e.g., a patient suffers a rash after receiving penicillin for a strep throat (which is appropriate) despite having a known allergy to that antibiotic) [36]. Drawing on each of these conceptualizations, we define "inappropriate health care" for this review as inappropriate clinical practices that may harm the patient, or when health care risks exceed the benefits. We will use the Institute of Medicine's [36] tripartite classification above of inappropriate clinical practices: (1) underuse, (2) overuse, and (3) misuse.

The purpose of the study described in this protocol is to conduct a systematic review of inappropriate health care in Canada to inform urgently needed quality improvement programs. This review will serve as a foundation of evidence-based knowledge for future progress in quality improvement provincially and nationally. Our specific objectives are to (1) systematically search and critically review published and grey literature for studies on inappropriate health care in Canada and (2) estimate the nature and magnitude of inappropriate health care in Canada and its provincial and territorial jurisdictions.

\section{Methods}

\section{Protocol and registration}

This protocol is reported following the Preferred Reporting Items for Systematic Reviews and Meta-Analyses Protocols (PRISMA-P checklist) [37]. The PRISMA-P checklist is included as an additional file [see Additional file 1]. This systematic review will be conducted in accordance with Cochrane's principles for systematic reviews [38], with adaptations for observational study designs which are frequently used in studies of inappropriate health care. This protocol is registered with PROSPERO no. CRD42018093495. Any amendments to this study protocol will be documented and filed with PROSPERO.

\section{Eligibility criteria}

We will include all quantitative study designs (e.g., randomized and quasi-randomized controlled trials, cohort, case-control, cross-sectional) reporting objective measurements (e.g., observation of practice, chart audits, administrative data) of inappropriate health care in Canada. We will also include subjective patient-reported measurements of inappropriate health care given some care processes are not routinely recorded in administrative data or patients' charts (e.g., counseling). We define inappropriate health care as inappropriate clinical practices. In this review, an inappropriate clinical practice is one that does not conform to clinical practice recommendations that are based on strong research evidence [2, 4, 5, 32] (e.g., use of antibiotics in viral illnesses). We define strong research evidence as synthesized evidence from provincial/national evidence-based clinical practice guidelines, provincially/nationally developed quality indicators, or systematic reviews/meta-analyses. All types of inappropriate clinical practices will be eligible: underuse (i.e., failure to provide a clinical practice when patient benefits clearly outweigh the risks), overuse (providing a clinical practice when its potential for harm exceeds the possible benefit), and misuse (an appropriate clinical practice was selected but a preventable complication occurs, and as a result, the patient does not receive the full potential benefit of the practice) [36]. All clinical practices (e.g., clinical problem identification/screening, diagnosis, assessment, intervention/treatment or follow-up) undertaken by any healthcare professional (e.g., physician, nurse) in a Canadian health 
care setting will be eligible. In line with previous reviews of inappropriate health care from other countries $[2,4,5,9]$, we will limit inclusion to studies that report on large or diverse populations, such as the entire nation, a province/territory, a city, or multiple $(>1)$ centers. No restrictions based on language or practice funding (e.g., public, private) will be applied.

\section{Search strategy}

Co-author (TR), an experienced information scientist, designed a sensitive search strategy informed by our scoping review [39] to retrieve studies from electronic bibliographic databases and grey literature sources. The search strategy was peer reviewed by an external librarian using the PRESS EBC Checklist, an evidence-based checklist for the peer review of electronic search strategies [40]. We limited our searching to Canadian studies from the last 10 years. See Table 1 for a search strategy for MEDLINE, which was translated for use in the other relevant electronic databases, including Cochrane Central Register of Controlled Trials, EconLit via ProQuest, and ISI-Web of Knowledge, which contains Web of Science Core Collection-Citation Indexes, Science Citation Index Expanded, Conference Proceedings Citation Index-Science, and Conference Proceedings Citation Index-Social Science \& Humanities. We will also search grey literature sources to identify provincial and national audits of inappropriate health care. This will include contacting and searching for quality reports on the websites of all provincial/territorial Ministries of Health, provincial health care quality organizations (all of whom are represented on our team), and provincial (e.g., Institute for Clinical Evaluative Sciences) and national (e.g., Canadian Institute for Health Information) administrative data facilities. Identification and access to these grey literature reports will be facilitated by our national team. Additional sources of data will be identified by reviewing reference lists of relevant publications/reports; contacting authors of relevant publications/reports to clarify published and/or seek unpublished information; and contacting Canadian researchers and knowledge users, internal and external to our team, who possess expertise in inappropriate health care.

\section{Data collection and analysis Identifying relevant literature}

Screening will be undertaken using the Distiller Systematic Review Program [41], an Internet-based software program that facilitates collaboration among reviewers during the study selection and data extraction processes. Two team members independently, using a two-step process, will assess the results of the published and grey literature searches. In level 1, all records will be assessed against three screening questions which we piloted on a sample of 287 abstracts from the
Table 1 Search strategy_Ovid MEDLINE

\begin{tabular}{|c|c|}
\hline$\#$ & Controlled vocabulary (MeSH) and text word search terms \\
\hline 1 & Health services research/ \\
\hline 2 & Health care reform/ \\
\hline 3 & "Health services needs and demand"/ \\
\hline 4 & Comparative effectiveness research/ \\
\hline 5 & Inappropriate Prescribing/ \\
\hline 6 & Quality Assurance, Health Care/ \\
\hline 7 & guidelines as topic/ or practice guidelines as topic/ \\
\hline 8 & "Quality of Health Care"/ \\
\hline 9 & (quality adj2 indicat*).tw. \\
\hline 10 & Delivery of Health Care/ \\
\hline 11 & or/1-10 \\
\hline 12 & Guideline Adherence/ \\
\hline 13 & Critical Pathways/ \\
\hline 14 & $\begin{array}{l}\text { exp Decision Theory/ or Decision Trees/ or exp Decision } \\
\text { Support Techniques/ }\end{array}$ \\
\hline 15 & $\begin{array}{l}\text { ((clinical or diagnostic or practice or practice or physician) adj3 } \\
\text { decision* adj3 (rule or tool or tools or pathway* or support* } \\
\text { or model or models or system or systems)).ti,ab. }\end{array}$ \\
\hline 16 & ((CDST or CDSTs) and decision).ti,ab. \\
\hline 17 & $\begin{array}{l}\text { ((pathway? or protocol? or algorithm?) adj2 } \\
\text { (clinical or treatment? or diagnos* } \\
\text { or management or infection? or infectious? or antibiotic?)).ti,ab. }\end{array}$ \\
\hline 18 & critical pathway*.ti. \\
\hline 19 & inappropriate.ti,ab,kf. \\
\hline 20 & (quality adj2 (improv\$ or manag\$ or care or healthcare)).ti,ab. \\
\hline 21 & $\begin{array}{l}\text { ((inappropriate or appropriate or overuse or overused or } \\
\text { over-used or over-use) adj2 (care or approach or health care } \\
\text { or healthcare or treat* or therap*)).ti,ab. }\end{array}$ \\
\hline 22 & or/12-21 \\
\hline 23 & $\begin{array}{l}\text { (canadian* or canada* or british columbia* or alberta* } \\
\text { or saskatchewan* or manitoba* or ontario* or quebec* or new } \\
\text { brunswick* or prince edward island* or nova scotia* or labrador* } \\
\text { or newfoundland* or nunavut* or northwest territor or yukon* } \\
\text { or toronto* or montreal* or vancouver* or ottawa* or calgary* } \\
\text { or edmonton* or winnipeg* or first nation* or metis).jw,ti,ab,hw,ot,kf. }\end{array}$ \\
\hline 24 & ((indigenous or aborig*) adj2 (people or person*)).ti,ab,kf. \\
\hline 25 & exp Canada/ \\
\hline 26 & Or/23-25 \\
\hline 27 & 11 and 22 and 26 \\
\hline 28 & limit 23 to yr="2007 - 2019" \\
\hline
\end{tabular}

MEDLINE search: (1) Was a quantitative study design used? (2) Is there measurement of inappropriate health care (or appropriate health care from which inappropriate health care can be derived) in a Canadian health care setting? and (3) Does the study report on a large or diverse population or on multiple centers? All potentially relevant records, as well as those that do not contain enough information to determine eligibility, will be retained. In level 2 screening, the full text of all 
retained records will be obtained and assessed for inclusion against the same screening questions. All discrepancies on whether a study meets the inclusion criteria will be resolved by consensus and, where necessary, by consulting a third senior team member. Reasons for exclusion will be documented.

\section{Data extraction}

Two team members will independently extract data from all included studies using a standardized data extraction form into the Distiller Systematic Review Program [41]; one team member will extract data which will be verified for accuracy by a second team member. Data extracted will include (1) study identification-authors, publication year, province/territory, language, publication status, funding, study design, data collection dates, and care category (preventive, acute, chronic); (2) participant characteristics-sample description (of both the patients receiving the care and the health care professionals delivering the care) including their gender/sex, age, education, and sample size, and for the health care professionals-role (e.g., physician, nurse) and experience; (3) clinical issue-descriptions of the clinical practice and funding source (e.g., retinopathy screening in diabetes mellitus, publicly funded), recommended service and evidence source (e.g., type 1 diabetes mellitus-screen for retinopathy every year, Canadian Diabetes Association Clinical Practice Guideline [42]); and health care setting (e.g., primary care clinic); and (4) outcomes-data source (e.g., administrative database) and details of the inappropriate health care-e.g., percentage of patients who experienced underuse, overuse, or misuse of the clinical practice. In studies where only appropriate health care is reported, where possible, we will extract data to extrapolate inappropriate health care. In longitudinal studies, we will focus our analyses on the last reported time point; in any experimental studies, we will focus on baseline measurements for trials with baseline data and on post intervention control group data in all other trials. Where necessary, we will obtain additional data through communications with original study authors. We have successfully pilot-tested our data extraction form on 5 published studies [43-47]; prior to commencing data extraction in the review, we will pilot, and refine if necessary, our data extraction form on a sample of grey literature. Disagreements in data extraction will be resolved by consensus and by consulting a third senior team member if needed.

\section{Methodological quality}

Strength or quality of evidence determines the level of confidence authors place in any estimates derived from the study [48]. Therefore, two team members will independently conduct a methodological quality assessment of each included published study and grey literature report.
Disagreements will be resolved through consensus and, if necessary, by consulting a third senior team member. Most studies on inappropriate health care, irrespective of whether it is a published study or in the grey literature, use cross-sectional designs (e.g., surveys, chart audits); we will assess these published studies/grey literature using the Quality Assessment and Validity Tool for Cross-Sectional Studies. This is a valid and reliable tool [49-55] developed based on medical literature $[56,57]$ and has been used in multiple systematic reviews of cross-sectional data (e.g., [49-55]). The tool uses 12 items to assess studies in three methodological domains: (1) sampling, (2) measurement, and (3) statistical analysis. Areas assessed under sampling include probability sampling, representativeness of the sample, sample size, number of sites, use of matching, and survey response rate. Areas assessed under measurement include main outcome measurement and its reliability and validity. Areas assessed under statistical analysis include statistical tests, $p$ values, confidence intervals, and missing data. An overall quality score between 0 and 1 is derived using total points scored/total points possible. Using this overall score, each study/report will be classified as of $<0.5$ weak, 0.50-0.74 moderate, or 0.75-1 strong methodological quality [50]. Other reliable and valid assessment tools will be used for published studies/grey literature that use other study designs as needed, e.g., the Revised Cochrane Risk of Bias Tool for Randomized Controlled Trials (RoB 2) [58] and Cochrane Risk Of Bias In Non-randomized Studies of Interventions Tool [59].

\section{Data synthesis}

This systematic review will require a narrative synthesis. We will organize our data into three categorizations of care: (1) preventive, (2) acute, and (3) chronic, preparing tables on each care category for Canada and for each province/territory where the data exists. This care categorization was chosen because there are important differences in the way each of these types of care is delivered that could affect whether or not care is inappropriate [2]. Preventive care is often initiated routinely by the clinician rather than on an episodic basis by a patient. The patient, on the other hand, typically identifies the need for acute care, which is frequently delivered during a single encounter. Chronic care is more likely than acute care to be delivered by a clinician who has an ongoing relationship with the patient [2]. These care categories were also used in the seminal US review of inappropriate health care [2] which led to multiple successful quality improvement initiatives [26]. Each table will contain data on setting, clinical practices investigated, sample, recommended service and its evidence source, study methodological quality, and inappropriate health care findings. We will develop a summary of inappropriate health care for each care category for Canada and each province/territory by calculating 
overall medians and ranges for underuse, overuse, and misuse of clinical practices (e.g., underuse, $45 \%$ of Canadians did not receive recommended preventive care). For clinical practices with a large number of included studies, we will calculate the interquartile range. We will conduct a sensitivity analysis to compare our median estimates in methodologically weak studies to all studies. Where data exists, we will also conduct subgroup analyses to determine whether inappropriate health care medians differ by (1) the evidential basis of the recommended practice indicator (i.e., by evidence source-clinical practice guideline vs. quality indicator vs. systematic review/meta-analysis), (2) the use of different measures of the same indicator, and (3) sex (women compared to men).

\section{Review quality}

We will use the Preferred Reporting Items for Systematic Reviews and Meta-Analyses (PRISMA) statement [60], a checklist of 27 items for transparent reporting of systematic reviews, in reporting our review. We will also use the AMSTAR 2 tool [61], a 16-item quality appraisal tool for systematic reviews, as a guide to ensure our review meets quality standards and to avert any possible deficiencies in the conduct and reporting of our review. We will assess and report on the quality of the evidence across all studies using the GRADE approach [62], which involves consideration of five categories: methodological quality (risk of bias), imprecision, inconsistency, indirectness, and publication bias. We will rate the evidence in one of four categories-high, moderate, low, or very low quality [62].

\section{Discussion}

\section{Potential challenges}

One potential challenge that we may face is locating and securing unpublished provincial/territorial audits of inappropriate health care. In anticipation of this challenge, we purposefully designed our team to include executive-level knowledge users and/or senior researchers involved in health care quality from all Canadian jurisdictions; they will facilitate identification and access to these audits. A second potential challenge is the likely heterogeneity between studies in how inappropriate care is defined and measured, which would limit our ability to statistically compare Canadian jurisdictions on the same clinical indicators. Therefore, our analysis is designed to summarize inappropriate health care in each Canadian jurisdiction rather than to statistically compare jurisdictions-this is also seen by our knowledge users as the most valuable and actionable type of analysis. We will also conduct a subgroup analysis if sufficient data is available to compare inappropriate care when different measures are used to capture the same indicator.

\section{Limitations}

Limitations to our review methods include relying on the identification of "recommended" clinical practices provided by the authors of our included studies. It is not feasible to assess the quality of the evidence behind each included study's identified recommended clinical practices. Therefore, in line with previous reviews on inappropriate health care from other countries $[2,4,5,9]$, we will rely on the study authors' identification of a "recommended" practice and document the evidence source provided. To ensure rigor, we will take several steps beyond what was done in the previous reviews; for example, we will limit inclusion to studies that provide reference to strong research evidence for their recommended practices: provincially/nationally developed clinical practice guidelines or quality indicators, or systematic reviews/meta-analyses. A second potential limitation to our methods is that some instances of inappropriate health care that will be identified may no longer be a problem today for a specified jurisdiction. To limit the likelihood of this occurring, we will restrict our searching to data collected in the past 10 years; according to our knowledge users, it takes at least 10 years to see trends in practice on which they would consider acting. A third possible limitation relates to the health care quality field in general; we will be able to capture only instances of inappropriate health care that have been studied, and therefore, our final estimates may be conservative.

\section{Conclusion}

This project will be the first-ever systematic assessment of inappropriate health care in Canada and its jurisdictions. We will be able to provide an urgently needed snapshot of inappropriate health care in Canada and to develop the first-ever evidence-based Canadian compendium of inappropriate health care. We will develop provincial and territorial jurisdictional reports summarizing both the nature and magnitude of inappropriate health care in each jurisdiction. These reports will serve to advance much needed quality improvement programs at the provincial, territorial, and national government's levels, as well as support agencies dedicated to quality and patient safety. It will enable the prioritization of programs and benchmark progress for quality improvement activities focused on improving health care quality and patient outcomes in Canadian jurisdictions.

\section{Additional file}

Additional file 1: PRISMA-P 2015 Checklist. (DOCX 37 kb)

Abbreviations

CIHI: Canadian Institute for Health Information; CWC: Choosing Wisely Canada; PRESS EBC: Peer Review of Electronic Search Strategies Evidence-Based Checklist; PRISMA: Preferred Reporting Items for Systematic Reviews and 
Meta-Analyses; PRISMA-P: Preferred Reporting Items for Systematic Reviews and Meta-Analyses Protocols

\section{Acknowledgements}

JES is supported by a Canadian Institutes for Health Research (CIHR) New Investigator award and University of Ottawa Research Chair in Health Evidence Implementation. IDG is supported by a CIHR foundation grant. JL is supported by a Canada Research Chair in Evidence-Informed Health Systems. FL is supported by a Canada Research Chair in Shared Decision Making and Knowledge Translation. CAE is supported by a Canada Research Chair in Knowledge Translation. AK is supported by a Manitoba Research Chair in Primary Prevention. JMG is supported by a Canada Research Chair in Health Knowledge Transfer and Uptake.

\section{Funding}

This research is funded by the Canadian Institutes of Health Research (CIHR). The funder had no role in the development of the protocol.

\section{Availability of data and materials}

We will include all data generated or analyzed during the systematic review in the published article [and its supplementary information files]. In case the journal does not provide support to publish the supplementary files online, the datasets generated and/or analyzed during the systematic review will be available from the corresponding author on reasonable request.

\section{Authors' contributions}

JES is the guarantor of this review. All authors participated in the conceptualization of the review, securing its funding, drafting of the study protocol, and development of the selection criteria, quality assessment strategy, data extraction criteria, and analysis plan. TR developed the search strategy. All authors read, provided critical feedback, and approved the final protocol manuscript.

\section{Ethics approval and consent to participate}

Not applicable.

\section{Consent for publication}

Not applicable.

\section{Competing interests}

The authors declare that they have no competing interests.

\section{Publisher's Note}

Springer Nature remains neutral with regard to jurisdictional claims in published maps and institutional affiliations.

\section{Author details}

${ }^{1}$ Clinical Epidemiology Program, Ottawa Hospital Research Institute, 501 Smyth Road, P.O. Box 201-B, Ottawa, Ontario K1H 8L6, Canada. ${ }^{2}$ Faculty of Health Sciences, School of Nursing, University of Ottawa, Ottawa, Canada. ${ }^{3}$ Faculty of Medicine, School of Epidemiology and Public Health, University of Ottawa, Ottawa, Canada. ${ }^{4}$ Registered Nurses' Association of Ontario, Toronto, Canada. ${ }^{5}$ Department of Health Research Methods, Evidence, and Impact, McMaster University, Hamilton, Canada. ${ }^{6}$ Population Health and Practice Changing Research, Research Centre of the CHU de Québec, Québec City, Canada. ${ }^{7}$ Department of Family Medicine and Emergency Medicine, Université Laval, Québec City, Canada. ${ }^{8} \mathrm{Health}$ and Social Services Systems, Knowledge Translation and Implementation Core, Quebec SPOR Support Unit, Montréal, Canada. ${ }^{9}$ Department of Surgery, University of Toronto, Toronto, Canada. ${ }^{10}$ Newfoundland \& Labrador Centre for Applied Health Research, Memorial University, St. John's, Canada. ${ }^{11}$ Department of Political Science and Faculty of Medicine, Memorial University, St. John's, Canada. ${ }^{12}$ Public Reports, Health Quality Ontario, Toronto, Canada. ${ }^{13}$ Institute of Health Policy, Management and Evaluation, Dalla Lana School of Public Health, University of Toronto, Toronto, Canada. ${ }^{14}$ Faculty of Nursing, University of Alberta, Edmonton, Canada. ${ }^{15}$ Information Management, Data, and Analytics, Health System Information Management Division, Ontario Ministry of Health and Long-Term Care, Toronto, Canada. ${ }^{16}$ Royal College of Physicians and Surgeons of Canada, Ottawa, Canada. ${ }^{17}$ Manitoba Centre for Health Policy, Department of Community Health Sciences and Family Medicine, University of Manitoba, Winnipeg, Canada. ${ }^{18}$ British Columbia
Patient Safety \& Quality Council, Vancouver, Canada. ${ }^{19}$ Institute of Health Policy, Management, and Evaluation, Department of Medicine, University of Toronto, Toronto, Canada. ${ }^{20}$ Department of Community Health and Epidemiology, Dalhousie University, Halifax, Canada. ${ }^{21}$ New Brunswick Health Council, Moncton, Canada. ${ }^{22}$ Patients Advisors Network, Toronto, Canada.

${ }^{23}$ Faculty of Medicine, School of Population and Public Health, University of British Columbia, Vancouver, Canada. ${ }^{24}$ Canadore College, North Bay, Canada. ${ }^{25}$ Health Quality Council of Alberta, Calgary, Canada. ${ }^{26}$ Canadian Agency for Drugs and Technologies in Health, Ottawa, Canada. ${ }^{27}$ Patient Collaborator, Toronto, Canada. ${ }^{28}$ Alberta Health Services - Alberta Cancer Prevention Legacy Fund, Population, Public and Indigenous Health, Calgary, Canada. ${ }^{29}$ Department of Family and Community Medicine, Institute of Health Policy, Management and Evaluation, University of Toronto, Toronto, Canada.

${ }^{30}$ Faculty of Health Sciences, School of Nursing, University of Ottawa, Ottawa, Canada. ${ }^{31}$ Manitoba Institute for Patient Safety, Winnipeg, Canada. ${ }^{32}$ Clinical Epidemiology Program, Ottawa Hospital Research Institute, Department of Medicine, University of Ottawa, Ottawa, Canada.

Received: 18 June 2018 Accepted: 14 January 2019

Published online: 11 February 2019

\section{References}

1. Deber RB. Access without appropriateness: Chicken Little in charge? Healthcare Policy. 2008;4(1):23.

2. Schuster MA, McGlynn EA, Brook RH. How good is the quality of health care in the United States? Milbank Q. 1998;76(4):517-63.

3. McGlynn EA, Asch SM, Adams J, Keesey J, Hicks J, DeCristofaro A, Kerr EA. The quality of health care delivered to adults in the United States. N Engl J Med. 2003;348(26):2635-45.

4. Seddon ME, Marshall MN, Campbell SM, Roland MO. Systematic review of studies of quality of clinical care in general practice in the UK, Australia and New Zealand. Qual Health Care. 2001;10(3):152-8.

5. Runciman WB, Hunt TD, Hannaford NA, Hibbert PD, Westbrook Jl, Coiera EW, Day RO, Hindmarsh DM, McGlynn EA, Braithwaite J. CareTrack: assessing the appropriateness of health care delivery in Australia. Med J Aust. 2012; 197(2):100-5.

6. Lavis JN, Anderson GM. Appropriateness in health care delivery: definitions, measurement and policy implications. CMAJ. 1996;154(3):321-8.

7. Lavis JN, Wilson MG, Grimshaw JM. Evidence brief: optimizing clinical practice in Ontario based on data, evidence and guidelines. McMaster: McMaster University; 2015.

8. Hampton J. Editorial comment - ideal treatment and appropriate treatment. Int J Cardiol. 2001;78:221-3.

9. Korenstein D, Falk R, Howell EA, Bishop T, Keyhani S. Overuse of health care services in the United States: an understudied problem. Arch Intern Med. 2012;172(2):171-8.

10. Morgan D, Dhruva S, Wright S, Korenstein D. Update on Medical Overuse: A Systematic Review JAMA Intern Med. 2016;176(11):1687-92.

11. Baker GR, Norton PG, Flintoft V, Blais R, Brown A, Cox J, Etchells E, Ghali WA, Hébert P, Majumdar SR. The Canadian Adverse Events Study: the incidence of adverse events among hospital patients in Canada. CMAJ. 2004;170(11):1678-86.

12. Wilson RM, Runciman WB, Gibberd RW, Harrison BT, Newby L, Hamilton JD. The quality in Australian health care study. Med J Aust. 1995;163(9):458-71.

13. Vincent $C$, Neale G, Woloshynowych M. Adverse events in British hospitals: preliminary retrospective record review. BMJ. 2001;322(7285):517-9.

14. Davis P, Lay Yee R, Briant R, Ali W, Scott A, Schug S. Adverse events in New Zealand public hospitals I: occurrence and impact; 2002.

15. Davis P, Lay Yee R, Briant R, Schug S, Scott A, Johnson S, Bingley W. Adverse events in New Zealand public hospitals: principal findings from a national survey; 2001.

16. Davis P, Lay-Yee R, Briant R, Ali W, Scott A, Schug S. Adverse events in New Zealand public hospitals II: preventability and clinical context. The New Zealand Medical Journal 2003;116(1183).

17. Schiøler T, Lipczak H, Pedersen BL, Mogensen T, Bech K, Stockmarr A, Svenning A, Frølich A. Incidence of adverse events in hospitals. A retrospective study of medical records. Ugeskr Laeger. 2001;163(39):5370-8.

18. Brennan TA, Leape LL, Laird NM, Hebert L, Localio AR, Lawthers AG, Newhouse JP, Weiler PC, Hiatt HH. Incidence of adverse events and negligence in hospitalized patients: results of the Harvard Medical Practice Study I. N Engl J Med. 1991;324(6):370-6. 
19. Leape LL, Brennan TA, Laird N, Lawthers AG, Localio AR, Barnes BA, Hebert $L$, Newhouse JP, Weiler PC, Hiatt $H$. The nature of adverse events in hospitalized patients: results of the Harvard Medical Practice Study II. N Engl J Med. 1991;324(6):377-84.

20. Thomas EJ, Studdert DM, Burstin HR, Orav EJ, Zeena T, Williams EJ, Howard KM, Weiler PC, Brennan TA. Incidence and types of adverse events and negligent care in Utah and Colorado. Med Care. 2000;38(3):261-71.

21. Choosing Wisely Canada. http://www.choosingwiselycanada.org/. Accessed 13 Sept 2017.

22. Bourne RB, Chesworth BM, Davis AM, Mahomed NN, Charron KD. Patient satisfaction after total knee arthroplasty: who is satisfied and who is not? Clin Orthop Relat Res. 2010;468(1):57-63.

23. Pimlott NJ, Hux JE, Wilson LM, Kahan M, Li C, Rosser WW. Educating physicians to reduce benzodiazepine use by elderly patients: a randomized controlled trial. CMAJ : Can Med Assoc J. 2003;168(7):835-9.

24. Hall R, Khan F, O'Callaghan C, Kapral M, Levi J, Cullen A, Wu J, Fang J, Bayley M. Ontario stroke evaluation report 2014: on target for stroke prevention and care. Toronto: Institute for Clinical Evaluative Sciences; 2014.

25. McAlister FA. The treatment of hypertension in Canada: are we making progress? CMAJ. 1999;161(6):713-4.

26. Bielaszka-DuVernay C. Health policy brief: improving quality and safety. Health Aff. 2011;32(1):1-7.

27. Institute for Healthcare Improvement. Protecting 5 Million Lives from Harm. 2017. http://www.ihi.org/engage/initiatives/completed/ 5MillionLivesCampaign/Pages/default.aspx. Accessed 13 Sept 2017.

28. Campbell SM, Roland MO, Buetow SA. Defining quality of care. Soc Sci Med. 2000;51(11):1611-25

29. Donabedian A. Explorations in quality assessment and monitoring. Volume 1: the definition of quality and approaches to its assessment. Ann Arbor: Health Administration Press; 1980

30. Sanmartin C, Murphy K, Choptain N, Conner-Spady B, McLaren L, Bohm E, Dunbar MJ, Sanmugasunderam S, De Coster C, McGurran J, et al. Appropriateness of healthcare interventions: concepts and scoping of the published literature. Int J Technol Assess Health Care. 2008;24(3):342-9.

31. Woodward RS, Warren-Boulton F. Considering the effects of financial incentives and professional ethics on 'appropriate' medical care. J Health Econ. 1984;3(3):223-37.

32. Sharpe VA, Faden Al. Appropriateness in patient care: a new conceptual framework. Milbank Q. 1996;74(1):115-38.

33. Buetow SA, Sibbald B, Cantrill JA, Halliwell S. Appropriateness in health care: application to prescribing. Soc Sci Med. 1997:45(2):261-71.

34. Leape LL, Park RE, Solomon DH, Chassin MR, Kosecoff J, Brook RH. Does inappropriate use explain small-area variations in the use of health care services? JAMA. 1990;263(5):669-72.

35. Hicks NR. Some observations on attempts to measure appropriateness of care. BMJ. 1994;309(6956):730-3.

36. Chassin MR, Galvin RW. National roundtable on health care quality. The urgent need to improve health care quality: consensus statement. JAMA. 1998;280(11):1000-5.

37. Moher D, Shamseer L, Clarke M, Ghersi D, Liberati A, Petticrew M, Shekelle $P$, Stewart LA. Preferred reporting items for systematic review and metaanalysis protocols (PRISMA-P) 2015 statement. Syst Rev. 2015;4(1):1.

38. Cochrane. Cochrane Handbook for Systematic Reviews of Interventions Edited by JPT H, S G, 5.1.0 ed. England: The Cochrane Collaboration; John Wiley \& Sons Ltd.; 2011.

39. Brien S, Gheihman G, Tse YK, Byrnes M, Harrison S, Dobrow MJ. A scoping review of appropriateness of care research activity in Canada from a health system-level perspective. Health Policy. 2014;9(4):48-61.

40. McGowan J, Sampson M, Lefebvre C. An evidence based checklist for the peer review of electronic search strategies (PRESS EBC). Evid Based Libr Inf Pract. 2010;5(1):149-54.

41. EvidencePartners. DistillerSR. https://www.evidencepartners.com/products/ distillersr-systematic-review-software/. Accessed 2018.

42. Boyd S, Advani A, Altomare F, Stockl F. Canadian Diabetes Association 2013 clinical practice guidelines for the prevention and management of diabetes in Canada: retinopathy. Can J Diabetes. 2013;37(Suppl 1):S137-S41.

43. Ackroyd-Stolarz S, MacKinnon NJ, Sketris I, Sabo B. Potentially inappropriate prescribing of benzodiazepines for older adults and risk of falls during a hospital stay: a descriptive study. Can J Hosp Pharm. 2009;62(4):276.
44. Kennedy J, Quan H, Ghali WA, Feasby TE. Variations in rates of appropriate and inappropriate carotid endarterectomy for stroke prevention in 4 Canadian provinces. Can Med Assoc J. 2004;171(5):455-9.

45. Lane CJ, Bronskill SE, Sykora K, Dhalla IA, Anderson GM, Mamdani MM, Gill SS, Gurwitz JH, Rochon PA. Potentially inappropriate prescribing in Ontario community-dwelling older adults and nursing home residents. J Am Geriatr Soc. 2004;52(6):861-6.

46. Mahant S, Peterson R, Campbell M, MacGregor DL, Friedman JN. Reducing inappropriate hospital use on a general pediatric inpatient unit. Pediatrics. 2008;121(5):e1068-e73.

47. Puyat JH, Law MR, Wong ST, Sutherland JM, Morgan SG. The essential and potentially inappropriate use of antipsychotics across income groups: an analysis of linked administrative data. Can J Psychiatry. 2012;57(8):488-95.

48. Owens D, Lohr K, Atkins D, Treadwell J, Reston J, Bass E, Chang S, Helfand M. AHRQ series paper 5: grading the strength of a body of evidence when comparing medical interventions--agency for healthcare research and quality and the effective health-care program. J Clin Epidemiol. 2010;63(5):513-23.

49. Estabrooks CA, Floyd JA, Scott-Findlay S, O'Leary KA, Gushta M. Individual determinants of research utilization: a systematic review. J Adv Nurs. 2003; 43(5):506-20.

50. Estabrooks CA, Cummings GG, Olivo SA, Squires JE, Gibin C, Simpson N. Effects of shift length on quality of patient care and health provider outcomes: systematic review. Qual Saf Healthcare. 2009;18:181-8.

51. Squires J, Estabrooks C, Gustavsson P, Wallin L. Individual determinants of research utilization by nurses: a systematic review update. Implement Sci. 2011;6:1.

52. Squires JE, Hutchinson AM, Bostrom AM, O'Rourke HM, Cobban SJ, Estabrooks CA. To what extent do nurses use research in clinical practice? A systematic review. Implement Sci. 2011;6:21.

53. Brady Germain P, Cummings GG. The influence of nursing leadership on nurse performance: a systematic literature review. J Nurs Manag. 2010;18(4):425-39.

54. Cummings GG, MacGregor T, Davey M, Lee H, Wong CA, Lo E, Muise M, Stafford E. Leadership styles and outcome patterns for the nursing workforce and work environment: a systematic review. Int J Nurs Stud. 2010; 47(3):363-85.

55. Cummings G, Lee H, Macgregor T, Davey M, Wong C, Paul L, Stafford E. Factors contributing to nursing leadership: a systematic review. J Health Serv Res Policy. 2008;13(4):240-8.

56. Kmet $L$, Lee $R$, Cook L. Standard quality assessment criteria for evaluating primary research papers from a variety of fields. Edmonton: Alberta Heritage Foundation for Medical Research; 2004: 1-22.

57. Khan K, ter Riet G, Popay J, Nixon J, Kleijnen J, Satge II. Conducting the review: phase 5 study quality assessment. In: Centre of Reviews and Dissemination University of York, editor. Undertaking systematic reviews of research effectiveness CDC's guidance for those carrying out or commissioning reviews; 2001. p. 1-20.

58. Higgins JPT SJ, Savović J, Page MJ, Hróbjartsson A, Boutron I, Reeves B, Eldridge $S$. A revised tool for assessing risk of bias in randomized trials. Cochrane Methods; 2016.

59. Sterne JA, Hernan MA, Reeves BC, Savovic J, Berkman ND, Viswanathan M, Henry D, Altman DG, Ansari MT, Boutron I, et al. ROBINS-l: a tool for assessing risk of bias in non-randomised studies of interventions. BMJ. 2016: 355:i4919.

60. Moher D, Liberati A, Tetzlaff J, Altman D. Preferred reporting items for systematic reviews and meta-analyses: the PRISMA statement. BMJ. 2009; 339. https://doi.org/10.1136/bmj.b2535.:b35.

61. Shea BJ, Reeves BC, Wells G, Thuku M, Hamel C, Moran J, Moher D, Tugwell $P$, Welch V, Kristjansson E. AMSTAR 2: a critical appraisal tool for systematic reviews that include randomised or non-randomised studies of healthcare interventions, or both. bmj. 2017;358:j4008.

62. Howard Balshem, Mark Helfand, Holger J. Schünemann, Andrew D. Oxman, Regina Kunz, Jan Brozek, Gunn E. Vist, Yngve Falck-Ytter, Joerg Meerpohl, Susan Norris, (2011) GRADE guidelines: 3. Rating the quality of evidence. Journal of Clinical Epidemiology 64 (4):401-6 